\title{
ROMANCE EMERGENTE Y LATINIDAD MEDIA
}

\author{
EULALIA RODÓN \\ Universidad de Zaragoza
}

El valor testimonial relativo a los orígenes de los romances hispánicos aportado por la documentación medieval latina anterior al siglo XI ofrece una acusada doble perspectiva. Por una parte la presencia de rasgos correspondientes al proceso general de vulgarización de la propia lengua latina, pero también la incorporación de nuevas formas en respuesta a los condicionamientos particulares de los diferentes ámbitos territoriales y a los respectivos tiempos y modos de su recepción del latín.

Bajo este último aspecto singulares factores de interés concurrirán en los textos procedentes de las comarcas del norte peninsular pirenaico. $Y$ en especial, y con mayor relevancia, cuando se trate de pequeñas células rurales, de agrupaciones poblacionales poco numerosas y aisladas, que reflejan el uso de un latín de acusado carácter vulgar, de grafías todavía vacilantes y de un léxico claramente marcado por la persistencia de hablas locales

En contraste con tan rico y prometedor acervo de ancestrales particularismos locales, encontramos excepcionalmente evidencias de una larga serie de correspondencias tanto entre las dos vertientes de la cordillera pirenaica como de uno a otro extremo de toda la zona del norte hispánico, testimonio, en todo caso, de unas innegables identidades lingüisticas estrecha y coherentemente relacionadas.

El antiguo monasterio de Codinet, en la comarca del Alto Urgel, situado junto a la orilla izquierda del río Segre, nos es conocido a través de una documentación que se extiende desde la primera mitad del siglo IX -su fundación puede suponerse posterior al año 815 y anterior al 829- hasta inicios del siglo XI, con su incorporación definitiva, en 1004, al monasterio de San Andrés de Centellas.

El Padre Jaime Villanueva', en su Viage literario a las Iglesias de España —n XII, Viage a Urgel y a Gerona- da noticia histórica del Mo-

' J. Villanueva, Viage literario a las iglesias de España, 1+XXII, Madrid y Valencia, 1803-1852.

RFE, LXXXI, 2001, 3. $.^{\circ}-4^{\circ}$, págs. 369-401 
nasterio de San Clemente de Codinet, acompañando la transcripción de dos pergaminos originales, ex autogr. in arch. Eccl. Urgell., que fijan los límites cronológicos antes señalados. El primero, una donación del año 829 , donde consta ya la existencia del monasterio como comunidad constituida bajo la autoridad del abad Sentefredo, y el segundo, de 1004, conteniendo el documento por el que Ermengol I, conde de Urgel, hizo donación, como alodio propio y a perpetuidad, del Monasterio de Codinet uniéndolo al de San Andrés de Centellas. Decisión que le había sido aconsejada, en Roma, por el Papa Gerberto, alio nomine Sylvestrum nuncupatum, y asimismo por otros obispos y abades, y motivada tanto por la extrema pobreza a la que había quedado reducida la Casa "que de hecho tenía enagenadas sus posesiones y perdidos sus libros y alhajas" —omnes possesiones et praedia monasterii ex toto alienatas, et venundatas, insuper libros pene abstractos et venundatos - como también por la "vida relajada y belicosa" del abad Osberno y de sus monjes: a recto itinere ita deviatos, ut prae nimia inopia vix in ipsis regulariter unus habitare potuisset monachus. Entre los libros del monasterio sabemos concretamente que figuraron las Sententiae de Tajón, según se desprende del testamento del Obispo de Urgel Sisebuto II, año 839, en el que disponía la donación de libros para varios monasterios, y entre estos Codinet: Do et concedo ad domum sancti Clementis monasterium sententiarum Expositum beati Taionis (Viage $\mathrm{X}$, ap.7).

Posteriormente, y ya en nuestros días, el Padre Cebrià Baraut, de la Abadía de Montserrat, publicó el conjunto de pergaminos del Monasterio de Codinet, compuesto en su mayor parte por los fondos conservados en la sección correspondiente del Archivo Capitular de la Seo de Urgel: "Diplomatari del Monestir de Sant Climent de Codinet, segles IX-xI" Studia Monastica 24,1982 y 26, 1984. A esta colección nos remitiremos con las siglas $M C o d$, o directamente sin indicación alguna, para la parte primera, y MCod II para la segunda, acompañando con el número y año de los documentos, salvo expresa mención de lo contrario.

A partir del año 815 , doce documentos del siglo IX, más veinte de la primera mitad del siglo $\mathrm{x}$ y diez de la segunda mitad $\mathrm{y}$ otros seis del siglo XI hasta el año 1042, constituyen el corpus escogido como objeto de nuestro estudio, omitiendo un breve de censos, de datación incierta pero indudablemente muy posterior a nuestras fechas. Caben también otras referencias al Monasterio que aparecen ocasionalmente en textos de otras procedencias, como las escuetas, pero importantes, menciones en el legado de libros a varios monasterios que figura en el testamento del Obispo Sisebuto Il de Urgel, o de tierras alodiales y animales domésticos en el del Conde Borrell II, testimonios ambos que también hemos recogido. 
Destaca sobremanera y ya de inmediato la variedad de formas bajo las que aparece la denominación de Codinet, referida bien al Monasterio bien a un lugar, o una villa o una iglesia.

Así para los cuarenta y dos documentos de los siglos $\mathrm{xX}$ y $\mathrm{x}$, entre 51 ocurrencias se registran en orden de frecuencia: Coteneto 22, Cutineto 13, Cotineto 10, Cuteneto 3, Chodenedo 1, Codineto 1, Guteneco 1.

$\mathrm{Y}$ para los seis documentos del siglo XI, hasta el año 1048, entre 7 ocurrencias: Codened 2, Cotinensis 2, Codeneto 1, Cotineto 1, Cutineto 1 (copia s. XIIs).

En orden cronológico, documento y año:

siglo IX: I, 815: Coteneto, Coteneto; 2, 829: Cotineto, Cotineto; 3, 837: Coteneto, Coteneto, Coteneto, Coteneto, Coteneto; 4, 840: Cotineto; 5, 846: Cotineto, Cotineto; 6, 853: Coteneto, Coteneto Coteneto; 7, 857-858: Codineto, Codineto; 8, 859: Cutineto; 9, 865: Cotineto, Cotineto; 10, 887: Coteneto; 11, 898: Cutineto; 12, 899; Coteneto,

siglo x: 14, 902: Chodenedo; 15, 904: Cotineto; 16, 908: Cutineto; 17, 924: Cotineto; 19, 928: Coteneto, Coteneto; 20, 928: Coteneto, Coteneto; 22, 933: Cuteneto; 23, 937: Cutineto; 24, 944: Cutineto; 25, 945: Cutineto; 26, 945: Guteneco; 27, 945: Coteneto; 28, 946: Cuteneto; 29, 947: Cutineto; 30, 949: Cutineto; 31, 950: Cuteneto; 32, 950: Cutineto, Coteneto; 33, 956: Cutineto; 34, 961: Cutineto; 35, 963: Coteneto; 36, 973: Coteneto, 39, 978: Cutineto; 40, 979: Coteneto; 41, 982: Coteneto; 42, 995: Cutineto,

siglo $\mathrm{xI}$ : 43, 1004: ecclesiam sancti Clementis, qui vocatur Cotinensis,... que vocatur Cotinensis; 44, 1010 (copia s. XIII): Cutineto; 45, 1016: Codeneto; 46, 1031: Cotineto; 47, 1041: Codened; 48, 1042: Codened.

Este abundante polimorfismo, rasgo por lo demás frecuente en la documentación de los siglos medios, en particular para topónimos, concurre también en las numerosas variantes que registramos en la denominación del río Segre:

En los siglos Ix-X: Secor, Secore, Segor, Segore, Sequer, Sequere. El orden de frecuencia, entre 11 ocurrencias es: Sequere 5, Segore 2, y para Secor, Secore, Segor y Sequer 1:

1, 815: in ribo Sequere; 3, 837: in Sequere rio; MCod II pág. 270, 840: prope flumen Secore ; MCod 5, 846: amne Sequere; 21, 929: in flumen Sequer; 23, 937: in flumen Sequere ...prope flumen Sequere; 26, 945: in flumen Secor; 27, 945: in flumen Segore; 36, 973: in flumen Segore; 42, 995: in flumen Segor.

$\mathrm{Y}$ ya en el siglo $\mathrm{XI}$, la forma Segre:

43, 1004: in flumine subtus se discurrente qui, nominatus dicitur Segre. 
Testimonios estos, sobre el nombre del río Segre, que revisten extraordinaria importancia para nosotros, pues aun en su brevedad, vienen a confirmar nuestra refutación a Corominas que expusimos en DLex $1326 \mathrm{~s}^{2}$.

Pues efectivamente Corominas, en $O_{\text {nom }}{ }^{3}$ s.v., dice del tio Segre que entre las variantes de las menciones antiguas catalanas, la forma más corriente desde la alta Edad Media era ya la moderna Segre.

Objetábamos nosotros, desde un principio, la escasa entidad probatoria de los textos por él aducidos, no ya tanto por ser muy pocos para sentar la base de una doctrina, como por tratarse de documentos no originales, cuando es precisamente en Toponimia donde la fiabilidad de las copias debe ser más cuestionada.

Y por el contrario, dentro del corpus que nosotros considerábamos, de documentación enteramente original, en el siglo $\mathrm{x}$, para 25 ocurrencias del nombre del río, en orden de frecuencia teníamos, entre 24 , las siguientes formas: Segore 7, Segor 5, Secor 3, Sequere 2, Sigeris 2, Seger 2, y Sechore, Secro, Sicor 1, y en el orden de su primera datación: Segore 918, Secor 920, Sequere 924, Sigeris 935, Segor 945, Seger 948, Sechore 948, Secro 959 , Sicor 999.

Frente a ellos encontrábamos un solo ejemplo para Segre, correspondiente al año 978 .

En los siglos XI y XII el polimorfismo no sólo no se reducía sino que era aún mayor, pero se definía ya otro orden de frecuencias en el que Segre ocupaba la segunda posición: Sigeris 19, Segre 12, Segor 9, Sicoris 8, Siger 7, Sigri 5, Sigerim 2, Sigor 2, y 1 para Secare, Secor, Seger, Segore, Segoris, Segri, Seguer, Seguris, Siccoris, Sichoris, Sigaris, Sigoris, Sigre, Siguris.

Los nuevos datos que en la presente ocasión hemos podido aportar, tanto por la variedad de formas, seis variaciones en tan sólo once ocurrencias -Secor, Secore, Segor, Segore, Sequer, Sequere-- como por las fechas tempranas de su primera datación, que aqui se adelanta a principios del siglo IX $-815,837,840,846 \ldots-$ frente a un solo ejemplo de Segre y ya al empezar el siglo XI, 1004, vienen a prestar una nueva corroboración a nuestras anteriores conclusiones enteramente contrarias a lo establecido por Corominas.

También, bajo otro aspecto, los nombres de los meses del año presentan variaciones formales que interesará recoger:

genouarii, genuarii, ianuarias, ianuarii, februarias, frebrorii, freubarii, frevoarii, marcii, martias,

\footnotetext{
${ }^{2}$ DLex: E. Rodón, "Documentación léxica latịno medieval pirenaica", Aragón en la Edad Media, XIV-XV, págs. 1325-1335.

${ }^{3}$ OnomC: J. Corominas, Onomasticon Cataloniae, I-VIII, Barcelona, 1989-1997.
} 
aprelii, aprelis, apriles, aprilis, madias, madii iunias, iunius iulias agustas, septembri, setemer octuber, octubres, octubri, octubrii, otubro, december, decembre, decembres, decembrii, decembris:

MCod II pág. 270, 840: ipsas kalendas ianuarias; MCod I 9, 865: sub die nonas ianuarias; 16, 908: .VIII. kalendas genouarii; 30, 949: .V idus ienuarii; 33, 956: .III. nonas ianuarias; 35, 963: .III. kalendas genuarii,

MCod II pág. 271, 901: idus frevoarii; $M C o d 115,904:$.I_kalendas freubarii; 31, 950: .VIII. kalendas frebrorii 34, 961: nonas februarias, 2, 829: .VII. kalendas martias; 32, 950: XIII. kalendas marcii; 39, 978: .II. idus marcii; 47, 1041: .V idus marcii, 12, 899: $X$. kalendas apriles; 14, 902: II. kalendas aprilis; 28, 946: $X$. kalendas apriles; 29, 947: XV. kalendas aprelis; 48, 1042: .VII. kalendas apretii,

19, 928: XV. kalendas madias; 20, 928: XV. kalendas madias; 25, 945 : kalendas madii; 43, 1004: .V. kalendas madii; 44, 1010 (copia s. XIII): .V. idus kalendas madii; 45, 1016: idus madii,

3, 837: sub die. VII . idus iunius; 6, 853: sub die. XXII. kalendas iunias, 24, 944: .VI. kalendas iulias; 27, 945: XV kalendas iulias,

18, 926: .III. kalendas agustas; 41, 982: die kalendas agusta,

36, 973: III. kalendas setemer; 40, 979: .VII idus septembri,

1, 815: sub die idus octubres; 11, 898: in mense otubro; 17, 924: VIX. kalendas octubri; 21, 929: .VIII. idus octubrit; 22, 933: .III. nonas octubrii; 37, 977: .VII. idus octuber,

5, 846: per ipsas kalendas decembres; 7, 857-858: sub die pridie klendas decembres; 8, 859: sub die .IIIX. kalendas decembres; 10, 887: .VII. kalendas decembris; 26, 945: XIII. kalendas decembrit; 42, 995: XVII. kalendas december; 46, 1031: .VIII. kalendas decembre.

La datación se completa referida al año del reinado de los reyes francos, introducido por regnante. Esta es la forma predominante en treinta y tres de cuarenta y ocho documentos. Sin embargo, ocasionalmente se encuentran las variantes: recnante, recnate, regegntem, regnantem, regnanti, regnate, renantem, renate:

20, 928: recnante; 6,853 : recnate; 17, 924: regegntem; 13, 901: regnantem; 22, 933: regnantem; 41, 982: regnantem; 48, 1042: regnanti; 34, 961: regnate; 12, 899; renantem; 11, 898: renate.

La vacilación en el uso de fórmulas estereotipadas, bien por desconocimiento de los términos usados o por inseguridad de la forma correcta, es el origen de numerosas particularidades en las grafias. 
Así ocurre en nullius cogentis imperio nec suadentis ingenio (o articulo) sed propria nobis et spontanea hoc elegit (o accesit) uoluntas, declarando obrar sin coacción ni engaño, espontáneamente y por propia voluntad.

"Frase frecuentemente deturpada"' dice de ella Menéndez Pidal citando variantes "en el extremo occidental del reino leonés, en Portugal":

nunlius quoque gentis inperio nec suadentis artigulo, 1049 Port.; nunlis quo[que] gentis inperio neque suadentis artigulo, 1061, León,

frente a:

nulliusque cogentis imperio neque suadentis artigulo, sed propia nobis accesit voluntas..., 1030 Sahagún, nullo me cogente sed propria voluntate, 1123 Port., Origenes $\$ 45,2$ y n $^{4}$.

Señalaremos en nuestros documentos, en cinco ocurrencias de la fórmula, para cogentis y para spontanea respectivamente, las siguientes formas: cogentis: cogentis, congentis, quegentis, quoegentis, quoquegentis, y spontanea: espontanea, expontanea, expontanea, expontanea, spontanea:

2, 829: nulliusque cogentis imperio nec suadentis ingenio set propria et expontanea nobis hec elegit voluntas; 3, 837: nullius quegentis imperio nec suadentis ingenio set propria et expontanea nobis elegit boluntas; 6 , 853: nulluus quoquegentis inperio nec suedentis ingenio set propriam et expontanea nobis accesit voluntas; 7, 857-858 nuliusque congentis imperio nec suadentis ingenio set propria et espontanea mihi hoc elegit bona voluntas; 10, 887: nullius quoegentis imperio nec suadentis ingenio set propria et spontanea mihi accesit bona boluntas.

Tanto en la especificación con que, al inicio de los documentos, es frecuente indicar la naturaleza contractual de su contenido como en las cláusulas introductorias de roboraciones o suscripciones, encontramos una serie de fórmulas que, partiendo de la base sustantiva carta (cartula), o scriptu$r a$, más una determinación adjetiva o genitiva -eleemosynaria, donationis, venditionis, ...-, se organizan en unas determinadas secuencias tipo como:

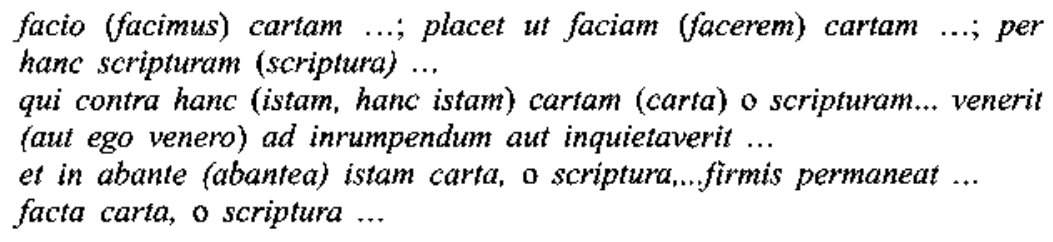

${ }^{4}$ R. Menéndez Pidal, Origenes del Español, Estado lingüistico de la Peninsula lbérica hasta el siglo $X I, 8 .{ }^{n}$ ed., Madrid 1976. 
qui hanc cartam, o scripturam,... feci (fecit, fecimus) et fieri volui (voluimus) ....

qui hanc cartam (carta)... scripsi (scripsit) ...

La opcionalidad de todas o varias de estas secuencias en un mismo documento al comportar la reiteración de sus componentes propicia el descuido y vulgarización en su uso y con ello abundante representación de variedades gráficas:

eleemosynaria: elemosenaria, elemosinaria, elimosinaria, helemosinaria, venditio, vinditio: vindictio, vindictionem, venditionis, vinditionis: bidicionis, bindicionis, bindilctionis, binicionis, binidicionis, vinddicionis, vindiccionis, vindicionis, vindictionis, vinditionis,

destacando además la particularidad de la concurrencia de distintas formas en un mismo documento, como vinditionis, vindictionis, bindilctionis en 6,853 ; binicionis, bindicionis, binidicionis, bidicionis en 11, 898:

6, 853: et in abantea ista carta vinditionis firmis permaneat. Facta carta vindictionis... Signum Qastremiti, Signum Cladies qui anc carta vindictionis facimus... Estetulfus presbiter, qui anc carta bindilctionis iscripsit; 11, 898: qui contra anc karta binicionis, beneri... Facta karta bindicionis...Sigum Adubira, Signum Onesta ... qui anc binidicionis fecimus ... Ego Centullus, qui anc karta bidicionis rogitus scrixi.

scriptura: iscriptura.

scripsi, scripsit: iscripsit, scripxit, iscripxit, iscrixi, scribsit, scrixi, cerixit,

incidentalmente recordaremos las soluciones gráficas análogas de: strata: istrata; stirpe: istirpe.

En los giros adverbiales in ante o in abante, in abantea, con ista carta o scriptura firmis permaneat recogemos las variantes: in abeantea, in avante, in avantea, in avantem, in evantea, in evanteat y también la forma ovantea, de lectura incuestionable, en 39, 978: in ovantea ista carta firmis permaneat.

La reiterada variación de formas, así como la fuerte dificultad que podía suponer la búsqueda de las adecuadas expresiones gráficas, tanto por el carácter vulgar de la lengua hablada como por el de los propios escribas, que a veces sólo ocasionalmente ejercían como tales, propician la aparición de términos particularmente problemáticos, a cuya solución sólo puede llegarse a través de un apretado análisis filológico. La comparación con contextos similares, buscando la equivalencia con términos conocidos, junto con el imprescindible cotejo paleográfico, nos ayudarán a llegar a su identificación. Identificación que en algunos casos extremos puede implicar la 
corrección de lecturas establecidas por el $\mathrm{P}$. Baraut en su benemérita labor de edición de estos textos.

Consideremos bajo este aspecto los siguientes términos: benam, avoni, avorno, abosos y vinea:

benam: Lectura confirmada en 15, 904: Dono ego Guistirla presbiter ipsa sorte de binea infra ipsas infrontationes ad domum sancti Clementi.. propter remedium anime me, ab integru ut benam merear abere ante tribunal Xpisti.

Para su identificación disponemos de los siguientes contextos similares:

17, 924: ut ante tribunal Domini nostri... Xpisti veniam mereamur accipere; 22, 933: ut ante tribunal domini nostri Ihesu Xpisti exinde veniam merear accipere; 30, 949: ut ante tribunal domini nostri lhesu Xpisti veniam merear accipere; 32, 950: ut ante tribunal Domini nostri Ihesu Xpisit veniam merear accipere; 33, 956: ut ante tribunal Domini nostri Ihesu Xpisti veniam merear accipere,

contextos estos que nos permiten considerar la forma benam como variante gráfica de veniam.

avoni: lectura confirmada en 12, 899: Vindimus ipsa vinia infra istas infrontationes avoni integritatem in aderato et definito precio...

Contextos similares como, entre otros:

1, 815: Et ipsam tertiam partem in iam dicta villa Coteneto vindo vobis $a b$ omne integrietate, ...; 3, 837: Bindimus... ipsa nostra portione iam dicta ... ab omni integrietate ..., ab omni integrietate vindimus tivi iam dicto Sentefredo in aderato et definito pretio; 11, 898: Binimus bobis ipsa terra ... ipsa duas partes ab omne integritate et recepimus de bos precio; 18, 926: Dono bobis ipsas terras et ipsas vineas et ipeas kasas ... et cultum et incultum quod superius resonat ab omnem integrietatem ...; 22, 933: Infra istas adfrontaciones sic dono ipsa terra ipsa ex medietate ad ipsa eclesia ab omnem integrigetatem propier remedium anime me,

que, con la inserción de avoni en su relación distribucional, nos permite interpretarlo como derivación gráfica de una forma vulgar de $a b$ omni como parte del giro $a b$ omni integritate en el texto examinado.

A su vez, las variaciones de los componentes del giro formular pueden seguirse en $a b$ omne integrietate $(1,815 ; 24,944 ; 25,945 ; 27,945 ; 28$, $946 ; 29,947) ; a b$ omni integrietate $(3,387 ; 7,857-858$ ?; 9, 865; 43, 1004; 44,1010 copia $\mathrm{S}$. XIII); ab omne integritate $(11,898)$; ab omnem integrietatem $(18,926 ; 19,928 ; 20,928 ; 23,937)$; destacando la forma integrigetatem en ab omnem integrigetatem $(22,933)$ de lectura comprobada. 
Añadiremos aquí las variantes de la modalidad alternativa del giro en $a b$ integru $(15,904) ; a b$ integre $(16,908) ; a b$ integro $(21,929)$; $a b$ integrum $(31,950 ; 41,982 ; 42,995 ; 45,1016 ; 48,1042)$; ab intecrum $(34,961 ; 35$, $963 ; 39,978 ; 46,1031 ; 47,1041) ;$ ab intecru $(36,973)$.

avorno: En 12, 899: Quem vero ipsa vinea cum ipsas arvores a nos vinditores traditu et a vos emtores recepta sunt de avorno (sic) die et tempore livera in Dei nomine aveatis potestatem.

De lectura segura y clara, tanto avorno como su contexto, sorprende que al editar el pergamino el $\mathrm{P}$. Baraut sintiera la necesidad de recurrir al (sic) que lo acompaña. No sería por ser forma desacostumbrada, ya que no lo hizo unas líneas antes al transcribir el término avoni, que acabamos de comentar ahora mismo, y que presentaba la misma problemática. Ya que no, por tanto, por duda o criterio paleográfico pueda quizás suponerse que no legase a encontrarle correspondencia con alguna palabra o con un significado.

Siguiendo con nuestro procedimiento habitual de análisis recurriremos en primer lugar al cotejo con contextos similares. Éstos serán los siguientes:

6, 853: ...ipsut terra a nos venditores tradito et a bos emtores recepto ut $a b$ odiermo die et tempore quiquit de ipsut terram ... agere ... voluberitis liveram et firmisimam in Dei nominem abeatis potestatem; 9, 865: dono adque concedo ... ut ab odierno die et tempore de ipsam.VI. partem ... quidquid facere ... volueritis libera et firmissima in Dei nomine abetis potestatem; 10, 887; ... ut ab odierno die et tempore quidquid exinde facere ... volueritis livera et firmissima in Dei nomine abeatis potestate; 24, 944: ...ut ab odierno die et tempore in Dei nomine abeatis potestate; 42, 995:... ut ab odierno die et tempore quieti et securi teneatis et possideatis ipsam terram; 47, 1041: sic vindimus vobis ipsas terras ... ut ab odierno die et tempore in Dei nomine abeatis potestatem,

también en plural, 41, 982: ...componere faciat, ut ab odiernis diebus et noctibus in omnibus abeant firmitate.

El giro ab hodierno die et tempore es suficiente en sí mismo, tanto gramatical como semánticamente, para expresar el equivalente de "de hoy en adelante", al igual que el giro alternativo ex presenti die et tempore que encontramos en 15,904; 16,908; 21, 929;25,945;28,946;29,947;31, 950; y en 48, 1042, aquí ex presentem die et tempore.

Pero, por otra parte, el carácter repetitivo y estereotipado a que tiende el lenguaje formular, propicia, en el habla viva, el encadenamiento de sus componentes, y de ahí la unión en secuencia VCV de la preposición $a b$ con odierno, con la consiguiente merma del sentido de su valor preposicional y 
dando lugar a la aparición de una nueva modalidad del giro $a b$ hodiemo die et tempore introduciendo el refuerzo de una segunda preposición como vemos en de ab hodierno die et tempore:

23, 937: dono ...de ipsa alia terra ... ipsa sua portione ab omnem integrietatem, ut de ab odierno die et tempore abeant potestatem; 27, 945: Quantum infra istas infrontaciones includunt ... sic damus ... ab omne integrietate ut de ab odierno die et tempore abeant potestatem; 35, 963: sic facio carta ... ut de ab odierno die abeas potestate omnique tempore.

$\mathrm{Y}$, con la formación del nuevo grupo fonético en el giro de abodiemo, por su repetición habitual y constante se llegaría al origen de una pronunciación vulgar en de aborno die et tempore recogida bajo la forma gráfica avorno merecedora de la extrañeza del autor de la transcripción del pergamino.

abosos: Mayor complejidad presenta abosos en 11, 898: recepimus de bos precio,... que bos entores dedistis et nos benitores de presente recepimus et nihicque de ipso precio abosos (sic) non remansi, es manifestum.

Aquí también, en la edición del Diplomatario de Codinet, el P. Baraut al dar la lectura abosos, y debido seguramente a la singularidad de la forma, cree necesario reafirmarla con (sic), pero queda no obstante abierto el problema de su dudosa interpretación.

Como contextos similares para su comparación disponemos de los siguientes:

8, 859: nobis placuit... ut bobis procambiaremus terra sicuti et facimus... et recepimus alia terra... quod bos dedistis et ego Gardilo manibus meis recepi et nihilque de ipsa terra procambiationis aput bos remansit, est manifestum,

12, 899: Vindimus ipsa vinia... in aderato et definito precio... quod vos emtores novis dedistis et nos venditores de presente manibus nostris recepimus et nihilque de ipso precio apud yos non remansit, est manifestum, 13, 901 (en MCod II pág. 169):... in aderato et definito precio... quod vos entores mihi dedistis et ego vinditor de presentem manibus meis recepi et nichilque vobis de ipso pretio aput vos non remansit, est manifestum.

MC 25, 945: recepimus de vos entores precio placibile... et nihilque de ipso precio aput vos entores non remansit, et est manifestum,

28, 946: recepimus de vos entores precio placibile... et nihilque de ipso precio aput vos entores non remansit, et est.manifestum,

y la misma fórmula, con aput te, en 1,$815 ; 3,837$ y 29,947 :

1, 815: et nihilque de ipso pretio aput te emtore remansit, est manifestum; 3, 837: et nicilque de ipso pretio aput te emtore remansit, manifestum est enim; 29, 947: et nichilque de ipso precio aput te entore non remansit et est manifestum, 
testimonios cuya comparación nos permite constatar que el cuestionado término abosos ocupa exactamente la misma posición distribucional y, aparentemente, desempeña idéntica función y posiblemente igual significado que el grupo aput bos, aput vos.

Si detenemos un momento nuestra argumentación para proceder a una apreciación global del documento en su conjunto, sobresalen de inmediato los rasgos de extrema tosquedad. Así, en un total de 220 palabras, incluyendo 24 nombres propios, se observan las siguientes particularidades:

a (ad), abeantea, aliqui, anc, anc, anc, ano, apate, balentes, bel, beneri, benerimus, benitores, bero, bestre, bestro, binere, binimus, binimus, cuatro ocurrencias de la voz vinditionis bajo cuatro grafias diferentes: bidicionis, bindicionis, binicionis y binidicionis, bobis, bobis, bobis, bobis bobis, bobis, bos, bos, consta, coponere, deveremus, entores, entores, es, ides, infront, infront, infronta, infronta, infronta, karta, karta, karta, karta, monesterio, nihicque, otubro, pau, permanea, precio, precio, remansi, scrixi, sera, su.

Destacaremos entre ellas las de bos, bos así como bobis, bobis, bobis, bobis, bobis, bobis, y bestre, bestro, como únicas grafias para vos, vobis, vestre y vestro, ya que a partir de ahí iniciaremos nuestra aproximación al análisis paleográfico de abosos.

Pues a diferencia del caso de auorno, donde la cuestionabilidad que el editor señalaba acompañándolo con (sic) no se refería a la lectura, absolutamente segura, sino a su significado desconocido, aquí por el contrario la duda empieza por versar sobre la propia transcripción, por el desciframiento de una escritura que presenta en parte rasgos confusos y que a nuestro entender no ha sido correctamente interpretada.

Por su probable equivalencia con aput vos, podría distinguirse en el abosos propuesto por el $\mathrm{P}$. Baraut, un primer segmento $a b o s$, resultante de $a$ (aput) bos, que respondería satisfactoriamente a lo esperado, quedando sin embargo pendientes dos dificultades. Una respecto al segmento siguiente $o s$, y otra concerniente a la grafía de la última letra de abos. Pues en todo caso tendría que aceptarse una $s$ de rasgos distorsionados, con una media circunferencia adosada a su parte inferior, rasgo que no presenta este signo en el resto del documento ni en la práctica paleográfica.

Nosotros, por nuestra parte, vemos en esta forma gráfica la resultante de dos signos superpuestos: una $s$ igual a las otras y una letra $b$, medio confundida con ella, de la que sobresale la parte inferior redondeada y compartiendo su parte superior con la forma $s$. Si observamos la escritura ahora, desde este supuesto, resalta de inmediato la correspondencia de estos rasgos descritos con los de la $b$ vecina en $a b o$. 
Tendríamos, así pues, un segundo segmento - bos, igual al bos anterior, repetición desde luego innecesaria pero no excesivamente extraña en textos de igual carácter que el nuestro. Así encontramos pplacuit, integrigetatem, imferam seo inferam, infero vel infero, inferam vel inferam, infront bel infront:

3, 837: manifesium est enim quia pplacuit animis nostris; 22, 933: dono ipsa terra. ... ab omnem integrigetatem...; 10, 887: imferam vel inferam; 15, 904: infero vel infero; 16, 908: inferam vel inferam; y en nuestro mismo documento 11, 898: infront bel infront.

Queda pues propuesta la sustitución de la lectura abosos por la nueva lectura abosbos.

A esta conclusión se ha llegado a partir de una base de criterios exclusivamente filológicos; de haber leído el paleógrafo directamente las dos letras superpuestas y transcrito abosbos, el procedimiento a seguir hasta la interpretación $a$ (aput) bos bos hubiera sido en sentido exactamente inverso.

vinea: vinea, vineas, vineia, vinga, vingas, vingeas, vinia, biga, binea, bineas, bineis.

Testimonio privilegiado de las vacilaciones en el uso de las grafias, a que antes nos referíamos como una de las más acusadas características de estos documentos, las que aquí aportamos presentan algunas particularidades que conviene subrayar.

Así su orden de frecuencia puede ser establecido en una doble escala: dentro del conjunto del corpus, $o$ bien en el texto en que se han registrado.

En el primer aspecto, las 86 ocurrencias del término se reparten en el siguiente orden: vinea 63 , binea 10 , vineas 4 , vinia 2 , y 1 para vineia, vinga, vingas, vingeas, biga, bineas y bineis. Con una proporción de 73 frente a 13 en el uso de $v$ y $b$, y destacando la emergencia de distintas variedades como representación gráfica de la palatalización de $n$.

vineia se encuentra en 12,899 Et infrontat ipsa vineia..., alternando con las formas vinea, vinia, vinea, vinea, cuyo conocimiento, por tratarse de un término de uso frecuente, no presupone el carácter culto del escriba. Por el contrario, la afloración de una grafia próxima a la lengua hablada se corresponde con la abundante presencia de rasgos vulgares en el texto: apindicio, arvores (y arboribus), deveremus, istirpe, livera, novis, novis, quislivet, renantem, supisana, suttus, vovis, vovis, vovis, vovis, vindiccionis, vindiccionis, vindiccionis, vindiccionis, vindiccionis, y los ya comentados avoni y avorno. 
biga en 15, 904: Et infrontat... et desuptus in biga. Con acompañamiento predominante de binea, binea, binea, binea, binea, binea, bineas y numerosas grafias vulgares: apati, balle, benerit, benero, bobis, bobis, est (ex), freubarii, integru, me, me, me (meae), monesterio, rogabi, seo (seu), serbiunt, serbire, y también benam, que vimos anteriormente.

vinga en 18, 926: Et ipsa alia in vinga qui est subtus kastro Mamakastri ... Como única ocurrencia en el documento junto a vinea, vinea, vinea, vinea, vinea, vinea, vinea, vineas, vineas, y a su lado vulgarismos como agno, agustas, bobis, espunsit, inbeniam, integrietatem, magestas, malledikat, monahi, monahi, monahi, monabi, obtaba, serbientes, serbiunt.

vingas, vingeas en 36, 973:... vindo vobis terras, vingeas, kasas, kasalibus... Quantum istas infrontaciones includunt sic vindo vobis ipsas terras et ipsas vingas et ipsas kasas...

A diferencia de los casos anteriores en vineia, biga, vinga, en este documento vingas y vingeas no tienen a su lado la presencia de ningún derivado de vinea o binea, pero sí, como en las otras ocasiones hay evidentes manifestaciones de características vulgares: ab intecru, abendicio, entoribus, exio, facia, infrontacionis, karta, karta, karta, karta, kasalibus, kasalico, kasas, kasas, orei, oreo, recresio, setemer, $s u$ (sub), vindicionis, vindicionis, volueri.

Por otra parte, en relación con esta última serie de grafias, contamos con los testimonios, algunos coincidentes, de Menéndez Pidal ${ }^{5}$ uinea, uinga, uingas, uinias, y de Oelschläger ${ }^{6}$ : binea, binga, venea, vina, uina, uinea, vinea, uinga, uinia, vinya, uinna, que confirman tanto la extensión del dominio lingüístico del término como la generalización de su pluralidad de formas.

No menor interés ofrecen nuestros documentos en su aspecto léxico, donde se ofrece la oportunidad de adelantar, a veces espectacularmente, primeras dataciones. Y ello teniendo además en cuenta que se trata siempre de documentos originales, que, en su lectura confirmada, evitan las dudas siempre pendientes sobre las formas tradicionalmente registradas sin que se haya señalado su originalidad o su condición de copia.

A estos efectos nos remitiremos a las siguientes obras con la referencia que indicamos:

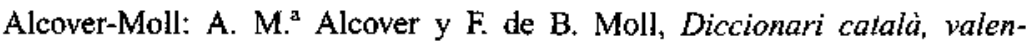
cià $i$ balear, I-X, Palma de Mallorca, 1926-1968.

Balari: J. Balari Jovany, Origenes históricos de Cataluña, Barcelona, 1899.

\footnotetext{
${ }^{5}$ R. Menéndez Pidal, cf. nota 4.

'V. R. B. Oelschläger, A Medieval Spanish Word-List, Wisconsin, 1940.
} 
DECat: J. Corominas, Diccionari Etimologic i Complementari de la llengua catalana, I-IX, Barcelona, 1980-1995.

DECH: J. Corominas y J. A. Pascual, Diccionario crítico etimológico castellano e hispánico, Madrid, 1979-1991.

$\mathrm{Mz}$ Pidal, Origenes: R. Menéndez Pidal, Origenes del español, Estado lingüistico de la península ibérica hasta el siglo XI; octava edición Madrid 1976.

Oelschläger: V. R. B. Oelschläger, A Medieval Spanish Word-List, Wisconsin, 1940.

OnomC: J. Corominas, Onomasticon Cataloniae, Barcelona, 1989-1997.

Pero quizás la mayor importancia y trascendencia de estos documentos radica en la extrema pobreza material y la ignorancia cultural que dejan traslucir. Desolador reflejo de las condiciones de vida de una comunidad de gente aislada, de relaciones transaccionales limitadas a contenidos de escaso valor.

Ausencia de mención directa a animales domésticos aunque sin embargo, ajeno a nuestro corpus, 'en el testamento de Borell II de Barcelona y Urgel, 23 de septiembre de 993, copia del siglo XIII, pero publicación sacramental del testamento de 13 de octubre del mismo año, original, se dice: Et ad sancto Andreo in Planicias equas. II. et vachas. II. Et ad sancto Clemente in Cutineto similiter. $Y$ en la publicación sacramental del testamento, documento original: et sancti Clementi in Chudineto iussit dare eguas. II. et vakas. II.

Menciones únicas de cupas y de furno, y única original de torculario, y una segunda, copia siglo xill:

cupas, 18, 926: facio karta elemosinaria de omnia mea alodem... idest terras et vineas et kasas et orreos ... et IIII. cupas ... Dono bobis ipsas terras et ipsas vineas et ipsas kasas cum suo superposita et cum exio et regresio et orreos, ipsas cupas et cultum et incultum.

furno, MC II pág. 271, 901: vindo vovis furno in territorio Montanione... Vindo vovis ipsum furno medio cum suos adetos ad omne intecrietate torculario, 18, 926: 18, 926: facio karta elemosinaria de omnia mea alodem ... id est terras et vineas et kasas ... et III. cupas ... Et ipso torculario medio et ipsa alia vinea ...; 44, 1010, copia siglo xul: facio ipsa karta helemosinaria de ipsas casas et ipso torculario et ipsa alia casa.

Sigue el repertorio léxico, indicando siempre la fecha de su primera datación en el Diplomatari de Codinet.

cabomas, desde 937:

procedente de caput mansus, el catalán capmàs es término antiguo que recoge Corominas en DECat s.u. romandre. En sentido estricto sería una casa de labranza principal con dominio sobre otras dependientes de ella, pero 
adquirió el valor más general de casa de labranza que poseía una importante extensión de predios.

23, 937: Et ipsa alia terra infrontat de.II. partes in torrente et de.III. in terra sancti Clementi. Quantum ista affrontaciones includunt sic dono de ipsa terra qui est in ipso cabomas ipsa.IIII parte ab integrum.

campo, campus, campos, desde 815:

Terreno extenso fuera de poblado, tierra laborable, asume de hecho el significado del latín ager. No es sin embargo frecuente en nuestros documentos que o bien se refieren a terras o pecias de terra, en general, o bien a un terreno cultum vel incultum.

Los primeros documentos de campo, en $D E C H$ son de 931, recogidos de Oelschläger, y para el catalán, en DECat, Corominas se remite, generalizando, a los orígenes del idioma pero concreta en la Crónica de Jaime I, Llull y Montaner.

Las muestras que aquí presentamos anticipan la datación de 931 a 815 :

1, 815: Et ipsam tertiam partem in iam dicta villa Coteneto vindo vobis $a b$ omne integrietate, idest in domos, curtes, edificia campos, arbores pomiferos et impomiferos, introita vel exita, aquis, pascuis,...; 6, 853: vindimus terram im paum Taustetano in locum ubi dicitur Coteneto in illo campo Sekalario; 7, 857-858?: et infrontat ipse campus desubtus usque in Cotineto. In quo bero ipse campus superius nominatus... dono, trado adque concedo... Si quis sane... si ego.... vel quislibet homo... pro ipso campo superius nominato.. inquietare presumpserit, inferant seu inferam ipso campo ad ipsa domum Sancti Clementi... dupplum perpetim abiturum; 10 , 887: Et est ipsa binea qui infrontat... in duas partes in binea et in terram nostra in appenditio de villa Coteneto in ipso campo Secalario; 41, 982: facio carta helemosinaria... Ad sanctum Clementem ipsa pecia de terra in ipso campo subtus sanctum Petrum

cannare, desde 815 :

cañar, cerco de cañas en los ríos para que entre la pesca. Nuestros testimonios anticipan en más de cien años las primeras manifestaciones señaladas por Corominas en DECat.

1, 815: vindo tibi in iam dicta villa omnem portionem mihi devita qui me expectat contra fratres vel eredes meos, quem abeo ex alode patris mei Laurici, id est, in ipsa villa tertiam partem et in ipso cannare qui est in ribo Sequere medietatem qualiter eum habuit pater meus Lauricus cum larnates; 3, 837: Ipsa portione nostra superius compreensam qui nos expectat in ipso iam dicto Coteneto cum ipso cannare medio qui est in Sequere rio... a nos vinditores traditum et a te emtore receptum abeas, teneas et possideas 
Çerba, serbero, desde 1031:

fruta generalmente silvestre, de color pardo y sabor áspero, de nombre ser$b a$ para el fruto y serbal para el árbol, en castellano y en gallego; en catalán, serva y servera o server. Existe sin embargo un cierto confusionismo entre $v$ y $b$ en ambos dominios y dado lo tardío de las primeras dataciones - Berceo y Arnau en Vilanova, siglos XII y XIV- bien puede asumirse una época común de indeterminación y una fijación posterior, y más aun por cuanto hoy en día coexisten tanto la una como la otra en variedades locales.

Interés por consiguiente el de nuestro testimonio por su gran anticipación cronológica, mediados del siglo XI, y por su forma en el nombre de un término en Codinet en el Alto Urgel.

46, 1031: Vindimus vobis .I. sorte de vinea in comitatum Orgello, in apendicio de sancti Clementi qui est in Cotineto, et est ipsa vinea ad ipsa Çerba; ib.: Quantum inter istas afrontaciones includunt sicut vindimus vobis ipsa sorte de vinea cum suis arboribus abintecrum in precio solidos ,III. et argencios. III. per ipso serbero, et est manifestum

ceresia, ceresias, desde 899:

procedente del latín vulgar ceresia y clásico ceresium, las formas cereza y cerezo vienen documentadas en $D E C H$ a partir de $c$. 1250 en el Libro de Alexandre para la primera y en 944 y 1210 para cereso y cerezo:

12, 899: vindimus vovis vinea in pau Orgelletano... ipsa vineia de superiore parte infrontat ad ipsa ceresia supisana.. Vindimus vovis ipsa vinia cum suis arboribus et ipsas duas ceresias

closello, desde 902:

extensión de tierra cultivable rodeada de un cercado, seto o muro de piedras. Esta palabra en su origen es un diminutivo de clausus del que deriva el catalán clos.

14, 902: Et afrontat ipsa terra qui est ad ipso closello de ,I. parte in strata publica, de alia in terra Sunifredo, de.III. in limitte, de.IIII in terra de Rechilde vel suos eredes.

comba, comas, desde 846:

valle pequeño en una hondonada o depresión del terreno. De origen céltico, como curvatura y valle pequeño, ha derivado en el castellano comba y el catalán coma. Su uso generalizado, ya desde antiguo, con valor toponímico -muy bien estudiado en Alcover-Moll y en DECat- puede verse comprobado en nuestros textos: 
5, 846: Et dono bobis adque concedo in Aras villa porcione mihi debita de terra... in ipsa comba porcionem mihi debita; et alia terra comba... quem abui cum fratre meo Teodosio ex medietate trado, dono adque concedo; 8, 859: et recepimus alia terra qui est locum que vocatur ad Comas...; 12, 899: vindimus vovis vinea in pau Orgellatano, in apindicio de villa Coteneto, in ipsas Comas; 26, 944: procamiamus vobis duas sortes de vineis et duas sortes de terras... quantum infra istas infrontaciones includunt sic procamiamus vobis... in ipsas comas; 47, 1041: Per hanc scriptura vindicionis vindimus vobis. II. fexas de terras qui sunt in Codened, ad ipsas Comas, in apendicio sancti Clementi

comella, comellas, desde 961 :

34, 961: Et infrontat de.I. parte in istrata... et de .III. in comella; 37, 977: et afrontat ipsa pecia de terra de .I. part in via qui pergit ubique et de alia in ipsa comella et de .III. in sponda; 41, 982: Et ipsa pecia de vinea adfrontat de.II. partes in ipsas comellas

condamina, desde 956:

de acuerdo con el sentido de su composición etimológica se refería en un principio a una casa de labranza incluyendo el dominio sobre todo aque1lo, tierras en particular, que pudiera corresponderle. De ahí pasó a consolidar su significado como predio, campo, extensión de tierra fértil y productiva:

33, 956: et est ipsa terra in ipsa Condamina.; 37, 977: I. pecia de terra in comitatum Orgello, in apendicio de sancto Tirso, in locum ubi dicitur in ipsa Condamina suptus Vallemaiore; 42, 995: ... placet ut ipsa terra qui est de sancta Maria Sedis Vico qui est in comitatum Orgellitense et est in apenditio de Novas promutare ipsa terra qui est prope ipsum cenobium, et ego sic commuto ipsas terras in ipsa condamina de Novas vel fintes eitus

congusto, desde 1004:

derivado de coangustum, congustum, en el bajo latín, al igual que angustum en el clásico, como camino estrecho, significó específicamente desfiladero, paso estrecho o angostura del cauce de un río entre montañas.

Balari recoge en el Viage del P. Villanueva -XXVIII 256 y XXIX462dos ejemplos: en el año 978 su uso como hidrónimo rivum Congustum, y en el año 1019 in flumine vallense quod discurrit per congosto. Incluye también del año 1004 la cita de un documento inédito que nosotros seguimos ahora en la edición del P. Baraut:

43, 1004: donamus ecclesiam sancti Clementis, qui vocatur Cotinensis... ad cenobium sancti Andree, qui est situs in comitatu Urgellensi infra congusto qui nominatur Interpontones 
cortel, desde 1042:

El catalán cortell, como espacio o terreno cercado adyacente a una casa, generalmente rural o de labranza, es citado en DECat s.u. cort en su forma antigua plural más cercana a la actual, en un documento de 1074, cortels. Muy próximo en la datación es también nuestro testimonio:

48, 1042: vindimus vobis kasas et terras... Et abent afrontaciones ipsas kasas de.I. part... et de alia part... et de .II. de vos comparatores, et quantum istas includunt sic vindimus vobis ipsas kasas et ipso cortel ab exio et regresio $a b$ intecrum et illorum superposita

eglesia, eiglesulam, desde 829:

Las primeras documentaciones de esta palabra en textos hispánicos son del año 921, en $D E C H$ s.u. iglesia recogiendo el testimonio de Oelschläger, quien además incluye otros de 940 y 950 . Corominas, por su parte, en DECat s.u. esglesia da "eglésia, docs. del s. xII". Puede verse por tanto el interés de comprobar su uso con la anterioridad de los ejemplos que aducimos:

2, 829: et ipsa insula que est in Cotineto, ubi ipsa eglesia et ipsa domum que ego Ilpericus tradidi Deo; $M C$ II, pág. 270, 840: et instuper damus ipsa insula qui est de ipsa eglesia... Hec homnia nominata damus... ad ipsa domum Sancti Clementi et fratres... de ipsa eglesia... ad opus monasterii ipsa eglesia vel quantum ad ipsa eglesia pertinet una cum abbatibus... vel quis ad ipsa eglesia deinde vibere voluerint; ib. : quislibet omo qui contra ahnc donationem... benerirmus vel benerint ad inrumpendum, inferam vel inferant ad ipsa eiglesulam dicta Sancti Clementis... dupplum vel tripplum quantum ad ipsa eglesia pertinet

fexa, fexas, desde 963 :

Anticipábamos nosotros mismos su primera datación a principios del siglo $\mathrm{x}$, a. 905 -fexas de terra.VII. - en DLex $1330-1331^{7}$, recordando alli también las fechas de 962 y 1007 en Alcover-Moll y 1019, 1026, 1049 y 1111 en Balari. En cuanto a Corominas, en $D E C a t$, parece en un principio limitarse a cumplir remitiendo directamente a Alcover-Moll y a bibliografia particularizada, aunque añade dos breves textos de Poblet, siglo XII, con dos variantes formales: fexam y faxam. A continuación, con su reconocida maestría, hace un detenido estudio de acepciones del significado y de variantes locales tanto en la pronunciación como en la escritura, de esta palabra muy presente en el habla y la toponimia de las zonas pirenaicas catalanas y alto-aragonesas.

\footnotetext{
${ }^{7}$ DLex, cf. n. 2 .
} 
Nuestros textos de Codinet:

35, 963: facio karta elemosinaria de .I. fexa de terra, ... sic facio carta a domum sancti Clemente de ipsa fex[a] de terra; 47, 1041: vindimus vobis .II. fexas de terras qui sunt in Codened

fonte, fontes, desde 846:

Como primeros testimonios $D E C H$ señala la forma fuant de un doc. de 938, en los orígenes del idioma, y fuent en Cid, en cita de Oelschläger, quien además da fuend, fuent, fonte, font y fuent en Berceo, fonte 938, font 1129. En $D E C a t$, Corominas después de una general "1. doc. origenes" remite directamente a Llull y a Martorell.

5, 846: Et dono bobis adque concedo... terra de ipsa fontes subteriore usque in villa et usque in strata; 7, 857-858?:: Et infrontat de parte... de Annesati sibe et per ipsa fonte terminatur unde aqua lebant ipsi homines de Aras

garricis, desde 815

Variedad de una especie enana de encina y, por tratarse de arbustos generalmente de poca altura se aplica al monte bajo, terreno sin cultivar poblado solamente de matas y arbustos pequeños. Corominas, DECat s.u garric, garriga, aporta documentación desde fecha muy temprana: a $843 \mathrm{ga-}$ rriga; a 977 garricis; a 978 garriga, ejemplos en todo caso procedentes de copias, seguidos de un ipsa Gariga en un pergamino "aquest original" que ya data de 1066 , en el siglo XI.

Antecedente en Codinet:

1, 815: Et ipsam tertiam partem in iam dicta villa Coteneto vindo vobis $a b$ omne integrietate, idest in domos, curtes, edificia, campos, arbores pomiferos et impomiferos, introita vel exita, aquis, pascuis, paludibus, silbis et garricis

Gissero, Guardia, desde 1004:

Afrontat in ipsa Guardia et descendit in ipso Gissero: el valor toponimico de estos dos términos, demarcativos de las afrontaciones del dominio territorial del Monasterio de Codinet - decisorio en este documento en que se actúa la donación y cesión a perpetuidad del propio Monasterio al Monasterio de San Andrés de Centellas- viene enfatizado y corroborado, no en el texto del pergamino original pero sí en la edición del texto, por su transcripción con mayúscula.

Pero a la vez el hecho de ir introducido por in ipsa... in ipso... implica su condición de apelativo, nombre común todavía vivo, respondiendo a características concretas o accidentes del terreno. 
Condición que hay que tener muy en cuenta, particularmente en lo que respecta al significado de guardia. Pues desde las primeras expediciones de los francos y la continuación hispánica de este primer impulso militar, se hizo imprescindible el establecimiento de puestos de vigilancia de los movimientos del enemigo: specula, speculum, miralio -de origen latino- o guardia, guardiola, procedente del franco y alto-alemán. Establecimientos que, tras un periodo de tiempo más o menos largo, quedaban atrás, sin efecto y olvidados en el avance geográfico de la Reconquista, pero que como "edificios o lugares equipados como puestos de vigilancia y custodia" dieron origen a numerosos topónimos, aplicados también a castillos y núcleos de población.

Sin embargo, y dado que los lugares aptos para el ejercicio de esta función de vigilancia militar debían reunir determinadas condiciones para prestarse a la observación de una amplia extensión de terreno circundante, el nombre, por analogía, paso a aplicarse, ya sin sentido técnico preciso, a lugares altos, eminencias del terreno, con un valor más próximo a mirador, y también montículo, y como apelativo pretoponímico pudo también dar a su vez origen a otros topónimos. $Y$ esta parecería ser la condición de nuestra Guardia, dada la de los otros términos con que está emparejada en su contexto inmediato: Roca Alba, Sisca, serra, puio, gradu, Gissero.

Gissero, por su parte, como yesar, terreno del que se extrae el yeso - es de notar aquí que para el castellano yeso, Oelschläger documenta gisso, en Tudela, en 1127-, tiene muy amplia representación en todo el territorio catalán: Guixers, El Guix, Guixera, Guixars.

En cuanto a las primeras manifestaciones, para Guardia Balari cita Guardia de Gelderico en 955 y Guardiola de Fluridio 992 y en 1067 un interesante: in puio vel loce que dicunt Guardiola que corrobora nuestras apreciaciones anteriores. Para Gissero, Corominas, OnomC, registra ad locum vocatum Guixer, en 1243, y dos Guillelmo de Guixeriis y Iohanni de Guixeriis en 1263.

43, 1004: Et hee sunt affrontaciones ecclesie Sancti Clementis que vocatur Cotinensis, ... de parte circi afrontat in ipsa Guardia et descendit in ipso Gissero

gradu, gradus, desde 937:

del latín gradus, paso, marcha, peldaño, del que proceden el castellano grado y el catalán grau, donde ha desarrollado varias acepciones metafóricas con valor toponímico, entre ellas el de paso o camino que va salvando con distintos niveles la ladera de una montaña abrupta. 
Las primeras documentaciones son de Menéndez Pidal, Origenes en Cid, citada por Oelschläger y $D E C H$, y para el catalán en Balari 1022 y 1081 añadiendo el diminutivo gradello en 997 y 1035.

Por nuestra parte en $\mathrm{NLugar}^{8}$ aportábamos testimonios más antiguos: de 885 en Eixalada 62, copia: in strata Francisca superiore usque in grado Redese; 898 A C Urgell, original: ... de alia parte affrontat in Gradu; 900 ib. original: et finit in Gradum de Caballeria: $913 \mathrm{~A}$ Condal 38: est affrontacio ipsius uallis in ipso grado de Lastanosa; y aquí, en 937 en Codinet:

23, 937: Et infrontat ipsa una terra de .I. partem in flumen Sequere et de alia in ipsos gradus et de .III. in stirpe; 43, 1004: Et hee sunt affrontaciones ecclesie sancti Clementis que vocatur Cotinensis, hoc est, ...et de meridie afrontat in ipsa serra que dicunt in Vilanova vel in ipso puio de Centullo et descendit in ipso gradu de Quolinules.

lebant, desde 857-858?:

Particular importancia adquiere el testimonio aquí aportado. Efectivamente, el Glossarium de Du Cange ${ }^{9}$ registra Levare: Paulus Diaconus Emeritensis in Vita S. Masonae Emerit. Episcopi cap. 2: Si quis... vas parvulum in quo Levaret exhibuisset. Hispanismus, en que llevarlo valet in quo deferret.

Asi decíamos en el XII C.I. de Lingüística y Filología Románicas, Bucarest 1969: "Desde el s. vII encontramos leuare con el valor de ferre, es decir como el castellano llevar. La primera documentación corresponde a las Vitas Patrum: licorem uini... poposcisset et uas parvulum in quo levaret exhibuisset; más tarde, en el s. $\mathrm{x}$ las Glosas de Cardeña dan ignifero: ignem lebante. Esta evolución semántica fue probablemente común a todo el latín hispánico, ya que también la tuvo el catalán antiguo (crónicas de Jaime I, Muntaner, etc.) aunque modernamente la haya perdido" 10 .

De la región oriental, Villanueva - Viage XVIII ap. 4- tiene un relato de la traslación del cuerpo de Santa Eulalia que dice: et assumptis prunis in uase testeo et misit os illud... Tunc cum laudibus et ympnis os illud leuauerunt de ipso igne et cum ipsis sociis suis coniuncxerunt, es decir: "sacaron el hueso del fuego"; en este pasaje leuare equivaldría a "sacar, retirar" en un estadio semántico intermedio entre el propiamente clásico y el de "Ilevar".

\footnotetext{
${ }^{8}$ NLugar: E. Rodón, "Nombres de lugar en documentos latinos medievales", Disputationes ad montium vocabula aliorumque nominum significationes pertinentes, 10. I.K. für $\mathrm{Na}$ menforschung, Wien, 1969, págs. 285-291.

Glossarium Mediae et Infimae Latinitatis, conditum a Carolo du Fresne, domino Du Cange, ed. nova a L. Favre, I-X, Niort, 1883-1887.

${ }^{10}$ E. Rodón, "El latín medieval como fuente para los orígenes de los romances hispánicos", Actele celui de-al XII-lea C.I. de Linguistica si Filologie Romanica, Bucarest, 1971, págs. 145-149.
} 
De ahí, por tanto, la relevancia de su uso en nuestro documento: per ipsa fonte... unde aqua lebant ipsi homines:

7, 857-858?: Et infrontat de parte. ... de Annesasti sibe et per ipsa fonte terminatur ipsa terra unde aqua lebant ipsi homines de Aras

linare, desde 945:

linar, campo de lino, castellano linar, catalán llinar. Anterior a la documentación de Codinet que aquí aportamos interesa añadir también un testimonio que registramos en el Diplomatario de la Catedral de Vich, editado por E. Junyent ${ }^{11}$, doc. 51, original, año 910: omnia nostra ereditate id est... in ortis, in terris, in linares...

Las primeras dataciones de linar son en Oelschläger linar 1060 -citado en DECH s.u. lino- y en Mz. Pidal, Orígenes, llinares et prados 1148. En cuanto al catalán, en Alcover-Moll linars en doc. de 1139.

27, 945: facimus karta elemosinaria ad domum sancti Clementi de una pecia de vinea et de una terra et de uno linare, ... Et ipse linare adfrontat de.l. parte in flumen Segore et de alias duas partes in terra sancti Clementi. Quantum infra istas infrontaciones includunt de ipsa vinea et de ipsa terra et de ipso linare sic damus ad domum sancti Clementi

maliolo, mallolo, desde 1016:

Diminutivo del latín malleus, martillo, malleolus se aplicaba ya en Columela y Plinio al sarmiento de viña cortado para plantarlo, y también, por extensión pasó a significar viña nueva. Por el uso generalizado del cultivo de la vid, en su adopción a los romances hispánicos revistió numerosas formas, estudiadas separadamente por Mz. Pidal en Origenes desde 979 magguelo, y en el siglo xI malguelo, malluelo, magguelo, malliolo, mallollu, mallolo, y recogidas y completadas por Oelschläger. En el catalán, DECat parte de un documento del siglo XI, 1043, y atestigua su abundante presencia en toponimia menor a través de varios derivados.

Desde el siglo $x$, años $979,980,981,990$ y 992 , podemos aportar textos de pergaminos originales procedentes del fondo de la Catedral de Urgel, con variedad de formas y de usos, sustantivo y toponímico:

a.979: vindimus vobis maliolus ... in loco que vocant Maliolas ... Et afrontat ipse maliolus de.I. latus in vine Elleberto et de alia in vinea ... et de.III. in vinea Eichone ... de ipso maliolo sic vindimus vobis ipsa nostra medietate.

a.980: vindo vobis vinea mea ... in loco que vocant Maliolas

${ }^{11}$ E. Junyent i Subirà, Diplomatari de la Catedral de Vic, Vic, 1980. 
a.981: Est ipsa vinae in loco que vocant Maliolas

a.990: carta faciamus ... de alodem ... nostrum ... et ipso malolo

a.992: et ipsa alia sortes de terra qui est ad illo maiolo de ipso Segalemo

\section{Y desde 1016 en Codinet:}

45, 1016: vindo tibi .I. mallolo qui michi advenit per plantacione; ib.: Et afrontat ipso mallo[lo] de.II. pars in vinea de sancti Clemencii et de.III. in ipsa strata; ib.: Quantum inter istas afrontaciones includunt sic vindo tibi ipso mallolo ab integrum; 46, 1031: Afronta ipsa vinea de.I. part in vinea de Guadamiro monacho, de alia in vinea Salomon, de .III. in maliolo de Gerberto

mulino, desde 840 :

En DECat, Corominas para el catalán, data las formas molin para el singular, y molins para el plural, en el siglo. XII. En cuanto a su pronunciación señala muli con $u$ no solamente como la propia del catalán oriental y el rosellonés, sino también como casi general en el catalán occidental hasta el extremo noroccidental en Ribagorza.

Esta es la pronunciación que como forma vulgar registran nuestros documentos en el área de Codinet, en el Alto Urgel, desde mediados del siglo IX.

$M C$ II pág. 270, 840: et insuper damus ipsa insula qui est de ipsa eglesia superius nominata una cum ipso mulino; $M C$ 5, 846: dono ad domum sancti Clementi in territorio Orgellatano in locum que bocatur Cotineto, terra coniacente super ipso mulino.

nocarios, desde 840:

Para el árbol de la nuez el catalán dispone de dos formas noguer masculino y noguera femenino, procedentes de nucarius y nucaria. En DECat, Corominas señala el predominio de la forma noguer en los textos antiguos, con ejemplos de 1030,1053 y 1184.

Nuestros nocarios confirman el género masculino en un documento procedente de la zona de Codinet, en el Alto Urgel, en el año 840:

MC II pág. 270, 840: damus ipsa insula qui est de ipsa eglesia superius nominata una cum ipso mulino et duos arbores nocarios.

obago, opaco, desde 950 :

del latín opacus, sombrío, cubierto de sombra, oscuro. De ahí, en toponimia, ladera septentrional de una montaña y, en general, para lugares poco expuestos al sol, correspondiendo al castellano umbria y al catalán obac, obaga. Muy frecuentemente usado en correlación con solano. 
De amplia proyección en su aplicación toponímica en el dominio lingüístico catalán, en el Alto Aragón, todo a lo largo de la cordillera pirenaica, llegando hasta Navarra, así como en amplias zonas del sur de Francia. Este uso tan extendido ha propiciado la aparición de gran variedad de formas que pueden básicamente seguirse en Balari, Alcover-Moll y DECat. En este último J. Gulsoy cita como primeras manifestaciones obago en 839 y como nombre de lugar Obac de Gironella en 1072, aporta además bibliografia particularizada.

Complementariamente podemos añadir aquí los testimonios que recogíamos, en 1972, en nuestro NLugar ${ }^{12}$ : 947 bag; 953 bago, 975 obago, 976 ubago, 978 bago, 983 bago, 984 Bag, 990 obago, 1017 bago, 1036 opago, 1118 opacho.

$\mathrm{Y}$ en Codinet:

31, 950: hanc carta vindicionis feci... de una vinea in comitatum Horgello, in apendicio de Cuteneto, in ipso opaco... et recepi de vos... vinea.l. qui est in ipso solano de Vallemaiore; 48, 1042: vindimus vobis kasas et terras... Et ipsa terra qui est ab ipso obago afrontat de.l. part...

oreo, orei, orreos, desde 926:

Los derivados del latín horreum, granero, se extienden a lo largo de todo el norte hispánico desde los dominios lingüísticos del gallego portugués y del asturiano hasta las zonas pirenaicas, perviviendo hoy en día en los medios rurales con un significado que desde el más próximo al originario, como edificio rústico de madera para guardar productos de cosecha, principalmente granos, se desplaza hasta significar entre los pastores del Pirineo chozas o cabañas para uso estacionario para el cuidado del ganado.

Como testimonios antiguos las formas orrea, 916, en C.S. Vicente de Oviedo, y en Oelschläger horreo $1080 \mathrm{~S}$. Juan de la Peña y orrio 1092 en Santona, mientras que para el catalán en $D E C a t$ no hay referencia a documentación antigua.

Aquí podemos aportar formas registradas en pergaminos originales procedentes de los fondos de la Catedral de Urgel, como:

895, horreo; 918, orreo; 924, orreos;, oreo; 961, orreo; 966, oreo,

y en Codinet:

18, 926: dono vobis ipsas terras et ipsas vineas et ipsas kasas cum suo superposita et cum sto exio et regresio et orreos, ipsas cupas et cultum

\footnotetext{
${ }^{12}$ NLugar, cf. n. 8.
} 
et incultum; 36, 973: vindo vobis terras, vingeas, kasas, kasalibus, orei, ...sic vindo vobis ipsas terras et ipsas vingas et ipsas kasas ab intecru et ipso kasalico et ipso oreo medio

ortis, desde 829

ortale, desde 982:

Del latín hortus derivan el castellano huerto y el catalán hort. Pero abundantes ejemplos en $\mathrm{Mz}$. Pidal, Origenes, de orto, ortos y orta en los siglos Xl y XII, y en especial orto, de 938, en San Juan de la Peña. En cuanto al catalán, en DECat, 1. doc. de hort remitida a "orígens, Llull, etc." y para ortales un doc. de 979, copia, y ortal, ya para el siglo xI.

Por nuestra parte tenemos registrado, procedente del fondo de la Catedral de Urgel, pergamino original, ortale en 961:

vindimus ... cassa cum curte ... et ipso ortale

$Y$ en nuestros textos de Codinet:

2, 829: nos tradimus ... terris, bineis, arboribus, ortis, ...

41, 982: facio carta helemosinaria... Ad sanctum Petrum .1. pecia de terra in ipso ortale

pago, pao, pau, paum, desde 853:

La palabra latina pagts, aldea, pueblo y comarca o distrito rural, tiene su primera documentación castellana en 1095, en documento leonés en Oelschläger, y se mantuvo viva bastante tiempo, aunque hoy día no es de uso habitual.

En $D E C H$ se indica que el vocablo desapareció en catalán muy pronto, pero no deja de recoger testimonios de su presencia en época arcaica, como pau, pauo, en escrituras del siglo ix y cita a Mz. Pidal -Origenes 268 - con in pao por in pago, en doc. de Ovarra, de 862.

Su uso por el contrario, es muy frecuente en nuestros documentos, en los que aparece bajo distintas formas, que reflejan una correspondencia con la lengua viva hablada:

3, 853: vindimus terram in paum Taustetatano; 11, 898: aliqui de terras nostras bobis binere deveremus sicuti et binimus bobis in pau Urgilitano, in loco ubi dicitur Cutineto monesterio; 12, 899: vovis vindere deveremus sicuti et vindimus vovis vinea in pau Orgelletano in apindicio de villa Coteneto; 14, 902: facio carta elemosinaria... ad domum sancti Petri alia sorte de terra in pao Orgilitano in apendicio sancti Iuliani vel de sancto Petro; 23, 937: facio karta helemosinaria ad domum sancti Clementi de.II. terras... in pago Orgellitano in territorio de villa Cutineto; 24, 944: pro- 
camiamus vobis... duas sortes de terras in pao Orgellitano in loco ubi dicitur Cutineto; 27, 945: facimus karta elemosinaria ad domum sancti Clementi de una pecia de vinea et de una terra et de uno linare... in pao Orgelletano inter villa Coteneto; 28,946 : vindimus vobis terra in pao Orgellitano, in loco ubi dictitur Cuteneto.

part, pars, desde 977:

Ya en DLex $1332^{13}$, y frente a las primeras manifestaciones en DECat referidas a las Homilies d'Organyà, aportábamos dataciones muy anteriores, desde el siglo $\mathrm{X}$, en los años $948,959,988$, con formas inequívocamente catalanas.

Corroboran este carácter y su antigüedad, así como la persistencia continuada de su uso, introduciendo además, repetidamente, el plural pars, los testimonios de Codinet en 977, 995, 1016, 1031, 1042:

37, 977: et afrontat ipsa pecia de terra de .I. part in via qui pergit ubique et de alia in ipsa comella et de.III. in sponda; 42, 995: Et infrontat ipsa terra de. III. pars in terra sancta Maria et de. III. vero part in flumen Segor; 45, 1016: vindo tibi .I. mallolo... Et afrontat ipso mallo[lo] de .II. pars in vinea de sancti Clemencii et de.III. in ipsa strata; 46, 1031: Afronta ipsa vinea de .I. part in vinea de Guadamiro monacho, de alia in...; 48, 1042: Et abent afrontaciones ipsas kasas de. I. part in kasas de Adalbert et de alia part in istrata et de.III. de vos comparatores...; ib.: Et ipsas terras de .I. part in terra de Senior vel filios suos, et de alia in terra de Bonifilio...; ib.: Et ipsa terra qui est ab ipso obago afrontat de.I. part de Trasver, et de alia part de Galindo presbiter, et de. III. part in terra filis Marcuço

plano, desde 979:

extensión de terreno de nivel igualado, llanura. Para el catalán pla, DECat señala como primeras manifestaciones en los origenes del idioma, la documentación del siglo XIII y Llull, y en cuanto a las formas plano y plan, siguen todavía vivas, más $o$ menos esporádicamente, como restos de fonética arcaica, en zonas pirenaicas, en los valles altos del Pallars y Ribagorza, Val Ferrera, Benasque, y aun con mayor extensión se encuentra fosilizado en su uso toponímico.

De ahí el interés de nuestro testimonio en 979 , al que podemos añadir con una mayor antigüedad, en docs. originales, procedentes del fondo de la Catedral de Urgel, el topónimo Planas en 935: in locum que vocant ad ipsas Planas; y plano con valor genérico y referido al mismo lugar, Posulas, de nuestro documento, en 977: alaude sancta Maria, qui est in Posulas in ipso plano.

\footnotetext{
${ }^{13}$ DLex, cf. n. 2.
} 
En TopMd ${ }^{14}$ dentro de los apelativos que por transferencia metafórica han pasado a designar accidentes geográficos y también nombres de lugar, incluíamos un amplio muestreo de extensión peninsular, del que entresacamos por su proximidad cronológica los siguientes: alio agro qui est in plano, 915 Becerro Gótico de Cerdeña; meam rationem... in plano, 917 C.S.V. de Oviedo; pecia de terra qui est in ipso plano, 966 fondo C. Vich; pecia una de terra... ubi dicunt ad ipso Plano, 968 ib.; in locum ubi dicitur ad ipsas Planas, 998 fondo C. Urgel.

40, 979; facio carta... de una sorte de terra in plano de Posulas

puio, desde 1004:

El podium del anfiteatro romano, y banco, asiento, también término técnico en arquitectura, ya en el siglo IV significó elevación en el terreno, y de ahí pasó a los romances como montículo o cerro, y luego incluso montaña alta. Menéndez Pidal en Origenes estudia las particularidades de las diversas formas con que aparece en la documentación antigua medieval, y en la toponimia aun hoy en día, desde el Mediterráneo, Cataluña, Aragón y Navarra hasta Vizcaya. Para el catalán, Corominas en $D E C a t$ pone la $1 .^{\mathrm{a}}$ documentación en textos literarios en el siglo xill pero en docs. desde fines del IX.

Desde mediados del siglo IX, 833: in loco dicitur ad Pogium, y en el $\mathrm{x}$ : 905, puiolo; 907, Poiregis; 935, puio; 938, pugolo; 961, Pugo Retondo; 968, puiolo; 970, Pugale; 975, puio, en pergaminos originales procedentes de los fondos de la Catedral de Urgel. Y sólo un ejemplo, a principios del siglo $\mathrm{XI}, 1004$, en los textos de Codinet:

43, 1004: Et hee sunt affrontaciones ecclesie sancti Clementis que vocatur Cotinensis... et de meridie afrontat in ipsa serra que dicunt in Vilanova vel in ipso puio de Centullo et descendit in ipso gradu de Quolinules

reo, desde 865:

Interesa documentar esta palabra que nosotros adscribimos al catalán rec a través de su forma rego presente en las fuentes medievales. Aunque de origen pre-romano su proximidad de significado y usos con el latín rigare ha dado lugar ocasionalmente a referirse no a canales o arroyos, sino a corrientes de agua de mayor caudal, así como a ciertas formas con vocalismo i: rigo, rigum. Pero estos casos de superposición o parcial identificación entre derivados de origen pre-romano y otros de origen latino, no son infrecuentes en el léxico de las regiones pirenaicas.

14 TopMd: E. Rodón, “Toponimia y Latín Medieval", Emerita, 40, 1972, págs. 273-286. 
La coincidencia de los giros pecias de terra qui sunt absque reo y qui non sunt subtus reo de nuestro texto con linare subreganeo, 924, terra subreganea 953; orto subreganeo 955 o terras vel vineas in rego, in subtus rego 940 , tierras de regadio, en C.S. Cugat ${ }^{15}$ corrobora nuestra interpretación de reo, al darle en su contexto, absque reo y qui non sunt subtus reo, valor contrario al de subreganeo, in rego, in subtus rego, y significar por tanto tierras sin acceso al cauce del agua, tierras que no son de regadio.

9, 865: donabi in territorio Elinsetano prope billa Nobas in quattuor pecias de terra, qui sunt absque reo qui non sunt subtus reo, qualis porcio me expectat de parentes meos inter eredes meos, idest.VI. partem ... ut ab odierno die et tempore de ipsam.VI. partem in ipsas pecias qui sunt absque reo quidquid facere, agere vel iudicare volueritis libera et firmissima ... abetis potestatem.

ribo, rio, desde 815 :

Frente a la primera documentación de rio en 912 que da $D E C H$ siguiendo a Oelschläger, o ya en el siglo xiIr, c. 1255-70 para el catalán riu, derivado del latín rivus, en $D E C a t$, nuestros ejemplos registran ribo y riu en 815 y 837 .

Por otra parte convendria matizar la afirmación de Corominas de que el sentido moderno de rio, como corriente de agua de relativa importancia, no lo adquiere hasta el siglo XIII, o que se usa el nombre del río sin el término genérico introductor, por ejemplo "passar Ebre", ya que en nuestros textos tenemos in ribo Sequere y también in Sequere rio

1, 815: vindo tibi in iam dicta villa omnem portionem mihi devita ... id est ... in ipso cannare qui est in ribo Sequere medietatem qualiter eum habuit pater meus; 3, 837: Ipsa portione nostra ... cum ipso cannare medio qui est in Sequere rio.

roca, desde 839:

De origen incierto, aunque sin duda prerromano, a partir de su significado primero, peñasco en el campo o en una montaña, se ve favorecido en su uso demarcativo para fijar los límites de las tierras objeto de transacción. También por razón de su altura, y más si se hallaba en una elevación de terreno, pasó a significar cerro, altozano, y así aparecía como lugar idóneo para el establecimiento de un castillo o fortaleza, de ahí castillo roquero de donde más tarde roca, ya por sí misma, como fortaleza o castillo.

is J. Rius Serra, Cartulario de San Cugat del Vallés, I-III, Barcelona, 1945-1947, IV, Indices, Madrid, 1981. 
Nuestra primera fecha de documentación, 839, coincide con la que da Corominas, partiendo de un texto no original.

12, 839: Et infrontat ipsa vineia de superiore parte infrontat ad ipsa ceresia supisana, suttus ipsa roca Laneri, de alia parte in istirpe et de.III. parte in torrentem; 43, 1004: Et hee sunt affrontaciones ecclesie sancti Clementis que vocatur Cotinensis, hoc est, de parte orientis afrontat in ipsa Roca Alba de Anseredo super ipsa Sisca.

Secalario, Sekalario, Sekalero, desde 853:

E] latín secale ha dado origen al catalán sègol, así como al francés seigle y al antiguo provenzal segle, segal, mientras que el castellano y el portugués centeno y centeio derivan de un latín hispánico centenum. Corominas en DECat da también para el catalán las variantes séguel, segle, y registra Fonte Sicolera procedente de un doc. de 920, copia.

Nuestro ejemplos corresponden al derivado segaler, segalar, como centenal, terrenos donde se cultiva el centeno, y de ahí su uso como topónimo.

6, 853: vindimus terram in paum Taustetano, in locum ubi dicitur Coteneto, in illo campo Sekalar[io]; 10, 887: ipsa binea ... infrontat ... in duas partes in binea et in terram nostra, in apenditio de villa Coteneto in ipso campo Secalario; 16, 908: aliquid donare deveremus in comitatum Orilietano, infra fines de vila Cutineto, in locum ubi dicitur Sekalero.

sementem, desde $846:$

Del latín sementis es palabra ya muy anticuada en el dominio del catalán, pero se mantiene todavía viva en Aragón y otras regiones. Corominas en $D E C a t$ da los primeros ejemplos en obras literarias, mientras que en el castellano, en $D E C H$, los fija en Berceo y se mantienen hasta ser sustituidos por semilla en el siglo XVII.

5, 846: Et dono bobis terra in balo Regines capientem sementem modiatas duas.

serra, desde 926:

El latín serra, sierra, instrumento de aserrar, en virtud de una metáfora se convirtió en "sierra, cadena de montañas". En Oelschläger hay ejemplos de la región castellana desde el siglo x: sierra 931, 1057 y Cid; y desde el siglo XI serra, 1011 y 1050 . En la región oriental, si bien la forma serra es coincidente con la latina, el significado romance es innegable, y así lo acepta Corominas, en DECat fijando la 1. a datación en 878. Y aunque señala su uso abundante en "moltissims docs. i cartorals que no calia ni em vagava de despullar", su siguiente registro es de 1150. 
En NLugar 16 aportábamos textos de serra y de sus derivados serrato, sarratum y seradallo, debiendo observar que los procedentes de Pallars eran copias, y originales los de A Condal Abadesas, Santas Creus y Urgel:

serra: 859, Pallars; 890, Urgel; 899, Pallars; 900, Urgel; 913, A Condal Abadesas.

Y los derivados:

serrato: 902, Urgel; serrato: 923, Pallars; sarratum: 974, Pallars; sera. dallo: 1067, CSantas Creus.

$\mathrm{Y}$ el testimonio de Codinet:

18, 926: Et ipsa terra qui est ad serra de Pesxes infrontat de una parte in strata, ...Et ipsa alia terra qui fuit de Ansalone et de suo patre infrontat de una parte in ipsa serra, de alia parte...; 34, 961: facimus karta... de .I. pecia de terra qui est in serra de Letirte; 43, 1004: Et hee sunt affrontaciones ecclesie sancti Clementis que vocatur Cotinensis, hoc est, ... et de meridie afrontat in ipsa serra que dicunt in Vilanova vel in ipso puio de Centullo et descendit in ipso gradu de Quolinules.

Sisca, desde 898:

De origen celta, sesca, planta gramínea que crece en lugares húmedos, es origen del castellano sisca o jisca, que pervive en las regiones de Murcia y Aragón. En cuanto al catalán, DECat no registra la voz sisca hasta el siglo XIV, pero los topónimos Sisquer o Siscar se encuentran desde los siglos IX y XIII.

Nuestros testimonios, de 898 y de 1004, no se referirán a una sola planta, sino que tienen valor colectivo de nombre de lugar.

11, 898: terras nostras ... binimus bobis in pau Urgilitano, in loco ubi dicitur Cutineto monesterio ad ipsa Sisca; 43, 1004: donamus hunc locum ad sanctum Andream cum suis terminis atque finibus ... Et hee sunt affrontaciones ecclesie sancti Clementis que vocatur Cotinensis, hoc est, de parte orientis afrontat in ipsa Roca Alba de Anseredo super ipsa Sisca.

solano, desde 950 :

ladera de una montaña o terreno en pendiente orientados al sol, y, en general, lugar donde da el sol. Se encuentra con frecuencia usado en contraposición a opaco, obago, sombrio, orientado a poniente, como vemos en nuestro documento 31: in ipso opaco... in ipso solano...

Como primeros testimonios Oelschläger da solano, 1073 San Juan de la Peña, y 1210 Santoña, datos que se recogen de $D E C H$, y para el catalán

\footnotetext{
${ }^{16}$ NLugar, cf. n. 8.
} 
Balari cita una escritura de 1035: in valle opaci... et in solano, pero ya para 947 registraba en un documento el plural Solanes como topónimo.

Aparte de los textos de Codinet, de 950 y de $977-978$, y anticipándonos a ellos, podemos añadir otros documentos, también originales, procedentes del fondo de la Catedral de Urgel, que remontan la primera datación al año 867, en el siglo $\mathrm{IX}, \mathrm{y}$ a. 941 , en uso toponímico: a. 867 in loco ubi dicitur ad illo Solano; a. 941: in locum qui dicitur Solanu.

$\mathrm{Y}$ en Codinet:

31, 950: hanc carta vindicionis feci... de una vinea in comitatum Horgello, in apendicio de Cuteneto, in ipso opaco... et recepi de vos precio ipsa vestra vinea .I qui est in ipso solano de Vallemaiore, et est manifestum; 38, 977-978: facio carta elemosinaria... de .I. sorte de vinea ad domum sancti Clementi. Est... vinea... in agacencias in ipso solano de Vallemaiore

sponda, desde 977 :

Por acepción metafórica, el latín sponda, armazón de la cama, pasó a usarse como orilla, borde de una canal o río, límite de un campo, en el aragonés espuenda y el catalán occidental espona, vasco exponda. Mz. Pidal, Origenes, 53,1, da las formas sponda, sponnal, sponnar en Cataluña, y spuenna, sponna, Spuanna en Aragón. En cuanto a la primera datación, Corominas, en $D E C H$ para el aragonés recoge de Menéndez Pidal spuenna en doc. de 1062 de San Juan de la Peña, y en DECat, para el catalán, se remite a Balari en un documento de 890: ipsa sponna de super rivo.

Por nuestra parte, en NLugar ya citado, dábamos abundante ejemplificación, partiendo de 852 :

a. 852 Pallars: ad illa sponda; a. 879 Eixalada: infrontat in sponda; a. 891 ib.: usque ad ipsam sponnam de super riuo; a. 910 Pallars: in ipsa nonna; a. 927 ib.: de occidente in sponna; a. 958 ACondal: infrontat ... in sa espoda (los textos de Pallars y Eixalada son copia, ACondal original), 'simismo las formas:

ipunga, Spunia, en doc. de a. 899, Urgel, orig.: terra qui est ad ipsa ia ... in locum ubi dicitur ad illa Spunga. nuestro testimonio en Codinet:

37, 977: et afrontat ipsa pecia de terra de.l. part in via qui pergit ubique et de alia in ipsa comella et de. III. in sponda

Las voces de la tierra, las sencillas palabras del día a día, del laboreo y de la siembra, del riego y de los pastos, con las que se ha nacido y nacieron los abuelos, fueron durante siglos para las gentes de esas pequeñas co- 
munidades aisladas y cerradas, parte de su propia identidad. Por ello, cuando una nueva forma de hablar y de ocasional escribir, latina y romance a la vez, se fue extendiendo tras un largo período de uso compartido, aquel fue el último reducto que nunca llegó a ser por completo olvidado. $Y$ así también hubo casos, cuando el sentido de ambos términos lo propiciaba, que antiguo y sobrevenido se fundieron en la práctica, sumando unas veces y otras intercambiando tanto la forma como el contenido de las palabras.

Ya lo expusimos al documentar la voz reo, que nosotros adscribimos al catalán rec. Palabra esta sin duda pre-romana, quizás ibérica, vascona o aquitana - por sus correspondencias tanto con el noroeste hispánico como en el vasco y el gascón - pero que por su proximidad de significado y de usos estableció identidades con la latina rigare. $\mathrm{Y}$ decíamos allí mismo que estos casos de superposición o parcial identificación entre derivados de origen pre-romano y otros latinos no son infrecuentes en el léxico de las regiones pirenaicas.

Pero ya anteriormente, en nuestro $D L e x$ ya citado confrontábamos las formas vetere y vedre en sus contextos, tratándose en principio, vetere de un derivado del latín vetus, viejo, antiguo y teniendo vedre, bedre, origen pre-romano. Palabra esta última, por cierto, que tanto en una como en otra de su doble forma gráfica, Corominas en DECat recaba como propias, no incluidas antes en diccionarios o repertorios, y que sin embargo figura con toda normalidad, bedre en Alcover-Moll s.v. con definición, localización de uso, y texto literario, y en grafia vedre, en el Tresor de la llengua de Grie$\mathrm{ra}^{17}$, con definición más amplia: "Porción de tierra inadecuada para el cultivo, y a veces y en parte con arbustos, que se reserva para pasto", o "dehesa" en Corominas, DECat.

$Y$ en el estudio de los usos de vedre y vetere demostrábamos cómo en los textos medievales que aducíamos se había producido una identificación de las dos voces, distintas en su origen, en una convergencia reinterpretativa a partir de sus valores originarios con el resultado final de que cada uno de los dos significados podía ser expresado con cualquiera de las dos formas.

$\mathrm{Y}$ dentro de este proceso de interrelación de dos registros lingüísticos en contacto, cabe encuadrar la doble forma de Vedrano, Vetrano que a continuación exponemos:

14, 902: facio carta elemosinaria ad domum sancti Clementi monesterii de. I. pecia de vinea et terra alia de terra, et ad domum sancti Petri alia sorte de terra... Et afrontat ipsa terra qui est ad ipso closello de.l. parte

${ }^{17}$ A. Griera, Tresor de la llengua, de les Tradicions i de la Cultura popular de Catalunya, I-XIV, Barcelona, 1935-1947. 
in strata publica, de alia in terra Sunifredo, de .III. in limite, de .III. in terra de Rochilde... Et ipsa terra qui est in ipso Vedrano afrontat de.I. parte in strata, de alia in terra de Asnario, de .III. in terra sancti Petro, de. III. in terra de Randemiro...

40, 979: facio carta a domum sancti Petri... de una sorte de terra in plano de Posulas in ipso Vetrano, et afrontat de una parte in terra Senderedo vel filis suis, de alia in terra Asnero, de tercia de sancto Petro, de IIII. in via antica.

En la comparación con testimonios en gallego portugués, encontramos vedro del "latín veteru, vello, antigo", familiarmente vedraño, como monte roturado donde se siembran cereales, también terreno que se deja sin sembrar, y finalmente terreno cercado con piedra o terrones.

Esta última acepción que se atribuye a vedro, vedraño, nos lleva a su relación con el catalán vedruna "hilera de piedras que delimitan una pieza de tierra" en Griera y a vedruna "hilera de mojones en tierras de pasto" en OnomC s.v. La Vedrenya.

Por otra parte podemos nosotros acentuar la relación de Vetrano con un origen en vetere, por medio de un nuevo testimonio, pergamino original de los fondos de la Catedral de Urgel, de 1051:

veteranos, 1051: Et ipsa alia pecia de vinea qui est in Ursian ad ipsos veteranos

donde si el uso de la forma veteranos puede sugerir tierra vieja, dejada sin sembrar, el plural por otra parte al indicar varias partes de un terreno podría aludir a su separación por medio de hileras de piedra.

Pero asumiendo los usos en gallego y su identificación allí con vedre y su pluralidad de significados, y con la relación a través de uno de ellos con el catalán vedruna, e insistiendo en la presencia en vedre del étimo vetus, por definición en el gallego como hemos indicado, y por nuestra parte demostrábamos en DLex, podemos concluir respecto a Vedrano, Vetrano que en primer lugar su doble forma tanto puede responder simplemente a doble representación gráfica como reflejar la identificación de dos orígenes distintos, y que en cualquier caso, se nos muestran con la posibilidad de asumir cada una de las acepciones consideradas.

En suma vedre, vetere, Vedrano, Vetrano y veteranos, son ilustraciones de la diversidad de factores y la complejidad de la interacción lingüística con que se vio condicionada la emergencia de las nuevas hablas romances en los siglos $1 \mathrm{X}$ y $\mathrm{X}$ en los medios rurales del norte peninsular pirenaico. 